\title{
COLOCAR POESIA NA FITA MÉTRICA
}

RESUMO: Este artigo propõe refletir acerca de algumas imagens do livro Atlas do corpo e da imaginação, de Gonçalo M. Tavares, feitas pelo grupo Os Espacialistas, a partir da relação pensada pelo autor e pelo coletivo entre corpo, arquitetura, espaço e movimento, em seu possível cruzamento com projetos heteróclitos como os de Aby Warburg e Georges Bataille, tomados na perspectiva de Georges Didi-Huberman.

PALAVRAS-CHAVE: atlas, corpo, espaço, arquitetura.

\section{PLACING POETRY ON THE MEASURING TAPE}

ABSTRACT: This article proposes a reflection with respect to some images of the book Atlas do corpo e da imaginação (Atlas of the body and imagination), by Gonçalo M. Tavares, made by the group Os Espacialistas (The Spacialists), starting from the relationship thought out by the author and the collective between the body, architecture, space and movement, in its possible links to heteroclite projects such as those of Aby Warburg and Georges Bataille, taken in the perspective of Georges Didi-Huberman.

KEYWORDS: atlas, body, space, architecture.

Em uma passagem do livro Breve notas sobre as ligações o escritor português Gonçalo M. Tavares diz: "As coisas estão repletas de nossos sentimentos. Olhar para uma coisa é tirar desta as sensações que nos pertencem e que ela havia guardado [raptado?] durante anos ou minutos. Olhar para as coisas é recuperar nelas o que era nosso" (TAVARES, 2010, p. 53). Roberto Esposito, no livro As pessoas e as coisas, aborda a experiência humana, em sociedades segmentadas pelas linguagens da religião, do direito e da economia, tendo em mente o atravessamento de uma linha distintiva: "O mundo da vida resulta cortado por um divisor de águas que o separa em duas zonas, definidas por sua oposição recíproca: ou se está do lado de cá, entre as pessoas, ou do lado de lá, entre as coisas, sem nenhum segmento intermediário que possa juntá-las" (ESPOSITO, 2016, p. 2). Para Esposito, nesse "binômio excludente", a dimensão verdadeiramente excluída seria a do corpo, sobretudo no plano do saber jurídico e filosófico, que tendeu a "remover de seu complexo a especificidade do corpo" (ESPOSITO, 2016, p. 4). Contudo, no declínio do cenário moderno, tal modelo dicotômico estaria cada vez mais enfraquecido:

Quanto mais os objetos técnicos incorporam, com o saber que os tornou fungíveis, uma espécie de vida subjetiva, tanto menor é a possibilidade de sufocá-los em uma função exclusivamente servil. Ao mesmo tempo, por

\footnotetext{
${ }^{1}$ Doutoranda em Literatura Comparada na Universidade Federal Fluminense. Mestre em Estudos Lusófonos pelo Departamento de Estudos Ibéricos e Latino-americanos na Universidade Sorbonne Nouvelle - Paris 3 (2014). Graduada em Letras pela PUC-Rio com habilitação em Português e Literatura de Língua Portuguesa (2007).
} 
meio do uso das biotecnologias, as que um tempo pareciam mônadas individuais, podem incluir dentro de si elementos oriundos de outros corpos e até de materiais inorgânicos. Dessa forma, o corpo humano passa a ser o canal de trânsito e o operador, sem dúvida muito delicado, de uma relação sempre menos redutível a uma lógica binária. (ESPOSITO, 2016, p. 3)

O livro Atlas do corpo e da imaginação, de Gonçalo M. Tavares, lançado em Portugal, em 2013, em parceria com o coletivo Os Espacialistas, dispõe a questão do corpo a partir de um quadrante temático - O corpo no método; o corpo no mundo; o corpo no corpo; o corpo na imaginação -, cujo eixo central parece se situar justamente na problematização relacional entre o corpo e as coisas. Já a nomeação do projeto como um "atlas" remete a um sentido limítrofe e heteróclito do livro como objeto. O termo "atlas", usado para designar, desde o final do século XVI, compilações ordenadas de conhecimentos geográficos ou astronômicos, remonta "à coleção de mapas de um mercador de 1585, que possuía como frontispício a imagem do Atlas, o titã da mitologia grega que carrega o universo, no limiar do encontro entre o dia e a noite" (BUCHLOH, 2012, p. 196). Mais adiante, o termo passaria a designar qualquer veiculação sistematizada de conhecimento em diferentes áreas como astronomia, geografia, anatomia, etnografia, etc. Já no século XX, em decorrência do declínio do ideal positivista, a acepção convencional do termo será problematizada por projetos como o Mnemosyne Atlas, do historiador de arte Aby Warburg. Neste sentido, a concepção do Atlas do corpo e da imaginação, pela sua estrutura e procedimento ${ }^{2}$ - e pela ordem heterogênea e fragmentária que coordena e articula a disposição e montagem das imagens, textos, títulos, subtítulos, notas de rodapé e legendas -, em uma aproximação lúdica e irônica a práticas de saberes totalizantes, acumulativas e classificatórias como os compêndios, as enciclopédias e os inventários -, parece de algum modo se aproximar de projetos como o de Aby Warburg, ou ainda do Atlas do artista alemão Gerhard Richter.

Extrapolando uma função meramente "ilustrativa", as imagens do livro de Gonçalo M. Tavares, feitas pelo grupo Os Espacialistas, compõem, ao lado dos textos, e na expressão do próprio autor, um “livro paralelo" (TAVARES, 2013, p. 528): “há o diálogo entre o textobase e as notas de rodapé; e depois as imagens, as legendas, os itálicos, que vão, sozinhos ou em conjunto, formando novas significações” (TAVARES, 2013, p. 529). Nas imagens, o

\footnotetext{
2 Segundo Delfim Sardo, o projeto do livro de Gonçalo M. Tavares tomaria por base a ideia do fragmento, tendo como ponto central desse fragmento a metáfora como processo, enquanto uma metodologia fragmentar metafórica.
} 
corpo é apresentado de múltiplas formas, compondo inúmeras cenas: em movimento, em posições inusitadas, em interações com outros corpos, materiais, objetos, espaços naturais e artificiais, em proporções convencionais ou ironicamente distorcidas pelo efeito óptico das fotografias.

O trabalho do coletivo Os Espacialistas ${ }^{3}$ se define como um "projeto laboratorial de investigação teórica e prática das ligações entre Arte e Arquitetura”. Partindo de uma ideia de "escrita fotográfica" o grupo propõe ações de intervenção nos espaços, norteadas por alguns conceitos ${ }^{4}$ : o exercício do "aparelho produtor artístico", entendido como um "órgão" disponível a todos, e que é trabalhado com as ações artísticas feitas pelo grupo; o trabalho de fazer aparecer a "vocação artística do espaço", a partir da ideia de que qualquer espaço pode revelar "apontamentos artísticos", nos quais seja possível ler "códigos" pertencentes ao repertório da arte contemporânea; a operação de gestos que se descobrem na manipulação do espaço, buscando-se construir narrativas com as várias imagens; a procura do lugar do corpo dentro do design ou da fotografia produzida.

A parceria de Gonçalo M. Tavares com o grupo pode ser compreendida como desdobramento de um desejo de ligação, presente de modo particular em alguns de seus textos, entre a prática da escrita e a da arquitetura, assim como da construção de um entendimento da espacialidade enquanto uma forma de pensamento entre, por exemplo, movimento e ética:

A arquitetura é uma selecção e uma escolha de movimentos, mais do que uma seleção apenas de objetos. Há movimentos que eu quero que sejam feitos neste espaço e há movimentos que eu não quero que sejam feitos neste espaço. Este é o poder dos arquitectos. Ora, isto é instalar no espaço uma filosofia de vida, uma filosofia de vivência de espaço. Se um arquiteto escolhe uma entrada muito baixa para entrar num espaço, que obriga as pessoas a curvarem-se, está a dar ordens num determinado sentido, está a determinar uma filosofia de acesso ao espaço. (TAVARES, 2011, p. 41)

\footnotetext{
${ }^{3}$ Verbete disponível no site da BoCA - Biennial of Contemporary Arts, bienal de artes contemporâneas que teve sua primeira edição em março de 2017, nas cidades de Lisboa e Porto. No verbete lê-se ainda: "Substituem o lápis pela máquina fotográfica, enquanto dispositivo de desenho, de pensamento, de percepção e de diagnóstico do espaço natural e construído, cujas ações são reguladas pelo Diário do Espacialista Por/tátil que transportam consigo. Entre os trabalhos realizados destacam-se projetos de arquitetura, exposições de fotografia, vídeos, instalações, espaços cênicos, performances, colaborações literárias, ilustrações fotográficas, oficinas, seminários e publicações”. O grupo teve seu início de atividade em 2008. In: http://www.bocabienal.org/goncalo-mtavares-e-os-espacialistas/ (Última acesso em: 15/08/2017)

4 Trecho a seguir baseado em transcrição a partir da reportagem sobre o coletivo realizada em dezembro de 2015. In: http://www.rtp.pt/play/p2258/e219786/makers/476973 (Último acesso em: 22/08/2017)
} 
Neste sentido, o trabalho da arquitetura seria exemplar na ênfase que confere ao atrito entre o essencial e o insignificante, como no caso do processo de transformação de uma projeção imaginária em algo material que não caia, que "não cause danos" (TAVARES, 2011, p. 32). Trata-se de uma atenção voltada ao que pode estar por trás dos pormenores, ou por trás dos movimentos corporais que estes exigem: "Mesmo os objectos têm uma filosofia. Utilizar um copo de plástico ou um de cristal altera toda a estrutura e toda a lógica. As cerimônias de chá japonesas, por exemplo, são pura filosofia dos objetos e dos espaços” (TAVARES, 2011, p. 40). Mesmo um objeto como uma simples cadeira: há um movimento, certos movimentos, certas escolhas, seleções e estudos acionados por um carpinteiro para viabilizar a execução da sua tarefa. Assim um arquiteto quando cria um espaço com suas coordenadas, dirige de alguma maneira nossa forma de andar, a inclinação do nosso corpo, pelo tamanho das janelas, a altura dos degraus de uma escada, de uma porta, etc.

Nesta perspectiva, a ação do arquiteto é pensada como possibilidade de interferência no trajeto existente entre o corpo e as coisas, e a construção como um "projecto humano de resistência ao animalesco" (TAVARES, 2011, p. 36). Em Arquitectura, Natureza e Amor, texto que contrapõe a espacialidade domesticada da cidade à espacialidade "animalesca" da natureza, a arquitetura é apontada como “o expoente máximo do acto de medir, de controlar" (TAVARES, 2008a, p.5). O ato de medir significaria, neste sentido, o desfazimento daquilo que não conhecemos, quando medir pode significar também "apagar a floresta" (TAVARES, 2008a, p. 3), apagar os avanços incontroláveis, "silenciosos, mas absolutamente eficazes, da floresta" (TAVARES, 2008b, p.11), operando gestos que acalmem no homem os materiais do instinto e do pressentimento:

Materiais concretos surgem no mundo humano apoiados/começados pela
fita métrica (o humano infiltrado na natureza: tentativa de dominar,
através da ordem do número, o animalesco que rodeia a cultura) enquanto
os materiais do pressentimento surgem no mundo humano apoiados pelo
instinto (instinto: esquecimento súbito, e com consequências, da
racionalidade - o animalesco infiltrado no humano). (TAVARES, 2008a,
p.5 No Atlas do corpo e da imaginação, na seção "O corpo no corpo" encontramos a imagem do mar com a linha do horizonte coberta pela linha de uma fita métrica, com a legenda: "1. Medir o horizonte. Fazer coincidir a fita métrica com a linha do horizonte. Se a linha do horizonte fosse mensurável, não seria impossível de alcançar". Mais uma vez, a ideia de um contraponto entre a natureza e o ato da medição humana. Na sequência, lê-se: "2. Tirar a poesia: medir. Extracção da substância poética: acto de medir. Colocar poesia na fita métrica: 
entortar". Em alguns poemas de Gonçalo M. Tavares não é difícil encontrar a ideia da espacialidade e da construção enquanto pensamento entre movimento e ética, como no poema do seu livro 1, intitulado "energia e ética":

Sei isto: a minha energia está canalizada Para a palavra fazer, gosto da ideia de construção E o que dela existe nos movimentos normais Agrada-me a palavra engenharia e o que ela Representa: não saias de um sítio sem deixares algo Atrás de ti. Dirijo-me apenas às coisas que me excitam Positivamente e me levam a fazer outras coisas, dirijo-me Às pessoas de que gosto, nunca às de que não gosto; Sempre me pareceu insensato que se pare, Nem que por um momento, de admira, há Sempre actos e coisas que nos ajudam Neste cálculo infernal da distância entre o dia de hoje e a nossa morte. E qualquer pessoa dar um passo que seja em direção ao que não aprecia, para insultar, ou derrubar, parece-me brutal perda de tempo, uma falha grave no órgão de admirar o mundo (deves combater uma ou duas vezes na vida, se combateres duzentas vezes é porque os combates são fracos). Não sei pois como viver. O que li e vi Serve-me apenas para ser mais lúcido, não Para ser melhor pessoa. Adquiri essa regra (ou nasci com ela): - e é talvez uma moral -

Mover-me apenas em direção ao que gosto.

Se o prédio alto, escuro, feio

Me impede de ver o sol, não fico a insultá-lo, não

Moverei um dedo para o deitar abaixo:

Contorno sim os edifícios necessários

Até chegar ao espaço de onde se possa receber aquilo que Quero. Se chegar lá de noite, montarei acampamento.

(TAVARES, 2005, p. 165)

Uma das definições encontradas no dicionário Houaiss para a palavra "atlas" estaria ligada ao registro da anatomia: "a primeira vértebra cervical, que se articula com a região occipital do crânio e o sustenta" (HOUAISS, 2009, p. 215). A vértebra é assim chamada porque esse é o corpo vertebral que suporta o peso da cabeça, funcionando como um apoio ao crânio. As vértebras axis e atlas na coluna cervical são diferentes de todas as outras pois seu desenho é o que possibilita a rotação da cabeça, ou seja, o seu movimento. As duas seriam, portanto, vértebras-limite, situadas justamente na passagem do corpo para a cabeça. Muitas das imagens presentes no Atlas do corpo e da imaginação jogam com a figuração da cabeça, como se, no livro, a ação poética dos Espacialistas de algum modo operasse nesse 
ponto de junção, de passagem, de articulação possível e lapso intermitente entre o corpo e a cabeça, ponto ora vazio, como em muitas figurações acefálicas, representadas por círculos brancos encobrindo os rostos, ora informe, como em "máscaras" com formatos e materiais incomuns, em que muitas vezes o corpo surge em uma fusão imagética com coisas, objetos, materiais. Assim, por exemplo, a imagem de homens com “máscaras" em forma de cadeiras", rostos tapados por fitas métricas, cobertos por tubos em formatos de cilindros, tábuas de madeiras, pedras, lama, terra, materiais de aço, etc. Mas frisar a acepção morfológica da palavra "atlas" nessas imagens é também tirar delas uma proposição determinante: a do lugar do pensamento enquanto um espaço de contato, de tatilidade, daquilo que se toca.

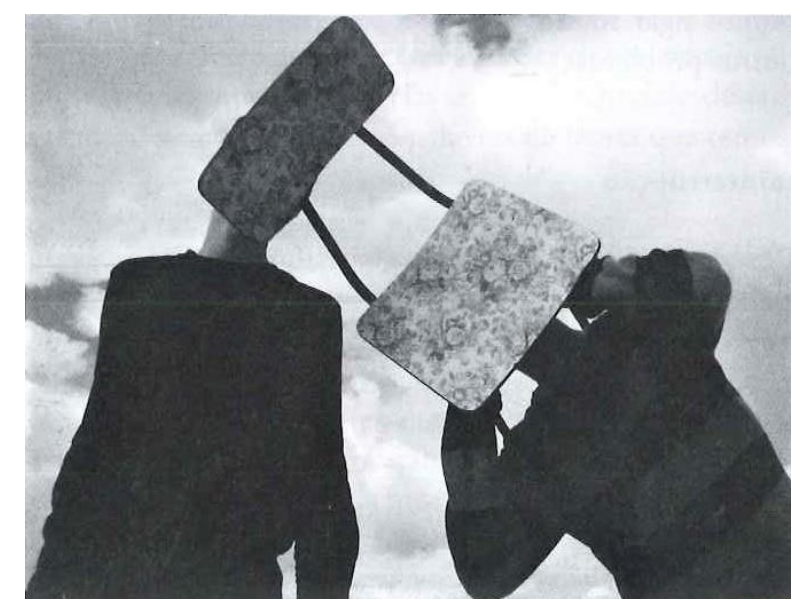

No livro Ser crânio. Lugar, contato, pensamento, escultura, com alguns desenvolvimentos acerca da obra do escultor italiano Giuseppe Penone, Georges Didi-Huberman lembra que Aristóteles pensou o coração como sede do pensamento, para, em seguida, a cabeça ter tido essa "honra". A partir da pintura São Jerônimo de Albrecht Dürer, Didi-Huberman fala da "mão do pensador que se apoia sobre o objeto de seu pensamento" (DIDI-HUBERMAN, 2009, p. 39), o crânio, ou caveira, ou seja, a mão de quem está pensando estaria apoiada sobre o lugar de seu pensamento. A questão refere-se ao entendimento sempre fugidio desse lugar:

Nada saber disso, desse lugar. Mas como ele tem presa sobre nós, como o alcançamos, como nos toca? Os artistas, sem dúvida não resolvem nenhuma das questões deste tipo. Pelo menos, deslocando os pontos de vista, revirando os espaços, inventando novas relações, novos contatos, sabem encarnar as questões mais essenciais, o que é melhor que acreditar responder a elas. (DIDI-HUBERMAN, 2009, p.36) [grifo do autor]

\footnotetext{
${ }^{5}$ Imagem (TAVARES, 2013, p. 210)
} 
No Atlas de Gonçalo M. Tavares, na parte intitulada "Mão, matéria e objetos", da seção "O corpo na imaginação", há uma sequência de imagens de um homem tentando entrar em uma parede, ou atravessar a parede ${ }^{6}$. Em um primeiro momento o que chama a atenção é justamente a ausência da cabeça, assim como dos braços, como se já parte do corpo estivesse "dentro" dela. Mais do que na parede, a cena, através do efeito óptico da imagem, nos leva a ver um corpo tentando entrar dentro de uma mancha na parede, que pode sugerir muitas coisas, como, por exemplo, a parte externa de um órgão sexual feminino, mas que também aponta para sentidos de tempo: a mancha, formada por pequenas rachaduras, é também

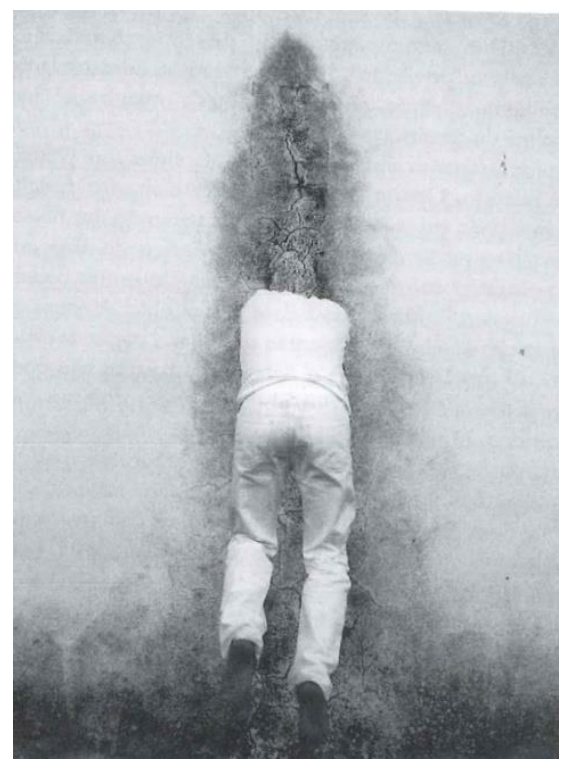

fenda, marca, vestígio, sedimento, pedra, uma erosão da matéria, um desenvolvimento, uma memória. Existe um desejo de escavação nessa imagem, no processo morfogênico de um espaço, um desejo de “imersão tátil” no lugar, seguindo uma expressão de Didi-Huberman. A provocação parece vir como pergunta: como entrar, penetrar, atravessar, fazer uma leitura tátil, leitura carnal, de contato, de textura do elemento que nos envolve? A ação espacialista nos joga nesta abertura/fechamento existente entre corpo e coisas, nesta fenda, neste lugar de pensamento, ao mesmo tempo que provoca um desmonte, um reviramento na apreensão objetiva, mental, positiva: o corpo está nas coisas, as coisas estão no corpo. Questão de forma, de informe, questão de transgressão em um sentido trazido por Georges Bataille, transgressão não como recusa, mas como a "abertura de um corpo a corpo, de uma investida crítica, no próprio lugar daquilo que acabará, num tal choque, transgredido" (DIDIHUBERMAN, 2015, p. 28):

\footnotetext{
${ }^{6}$ Imagem (TAVARES, 2013, p. 340)
} 
Reivindicar o informe não quer dizer reivindicar não-formas, mas antes engajar-se em um trabalho das formas equivalente ao que seria um trabalho de parto ou de agonia: uma abertura, uma laceração, um processo dilacerante que condena algo à morte e que, nessa mesma negatividade, inventa algo absolutamente novo, dá algo à luz, ainda que à luz de uma crueldade em ação nas formas e nas relações entre formas - uma crueldade nas semelhanças. Dizer que as formas "trabalham" em sua própria transgressão é dizer que esse "trabalho" - debate tanto quanto agenciamento, laceração tanto quanto entrançamento - faz com que formas invistam contra outras formas, faz com que formas devorem outras formas. Formas contra formas e, vamos rapidamente constatá-lo, matérias contra formas, matérias que tocam e, algumas vezes, comem formas. (DIDIHUBERMAN, 2015, p. 29)

Tal sentido do informe surge como algo decisivo para a abertura de uma nova maneira de se pensar as formas, e o resultado disto será o próprio trabalho das vanguardas artísticas e teóricas das primeiras décadas do século XX. Mas se o possível contato que a narrativa iconográfica do grupo Os Espacialistas realiza com certo repertório vanguardista abarca o sentido de informe é para de algum modo incorporá-lo e fazer dele algo diverso: um sentido que se daria sobretudo através de um acto de medição, ou ainda, de um informe que se surge como consciência em uma medida hiper-realista: "Colocar poesia na fita métrica: entortar".

Discorrendo acerca do procedimento de Aby Warburg, Georges Didi-Huberman lembra que o historiador alemão prendia as imagens do seu atlas com pequenos grampos em um pano preto pendurado sobre uma moldura, um "quadro", ao que então tirava ou fazia alguém tirar uma fotografia, obtendo assim um "possível painel” ou "prancha" do atlas, para em seguida desmanchar, "destruir" o painel inicial, e "recomeçar um outro para o desconstruir novamente" (DIDI-HUBERMAN, 2011, p. 21) [tradução nossa]. DidiHuberman fala da loucura de "telas proliferantes", desafio ostensivo à toda razão classificatória, mas igualmente uma sabedoria e entendimento, em um outro sentido: "Warburg havia compreendido bem que o pensamento é um domínio, não de formas encontradas, mas de formas transformantes. Domínio de 'migrações' (Wanderungen) perpétuas, como gostava de dizer" (DIDI-HUBERMAN, 2011, p. 22), quando mesmo a dissociação é suscetível de análise, de remontagem, através de imagens dialéticas colocadas em choque ou em ligações de singularidades entre si:

Nem desordem absolutamente insana, nem ordenação muito sábia, o atlas Mnémosyne delega à montagem a capacidade de reproduzir, pelo encontro das imagens, um conhecimento dialético - sem síntese, portanto - entre razão e desrazão, ou como dizia Warburg, entre astra, que nos eleva em direção ao céu do espírito e monstra, que nos relança aos abismos do corpo. (Idem) [tradução nossa] 
Duas dimensões, monstra e astra, formulação de uma dualidade entre coisas viscerais e coisas siderais, "reunidas" assim sobre a mesma tela ou a mesma "prancha". Gestos de amor, e "gestos de combate, gestos de triunfo e de escravização, de elevação e de queda, de histeria e de melancolia, de graça e feiura, de desejo em movimento e de terror petrificado" (DIDIHUBERMAN, 2011, p. 24). Assim, segundo Didi-Huberman, Warburg procura mostrar esta energia sobre um fundo que denominava como um "limite conflitual", o "impensado", a zona do "não-saber", astra, de um lado, monstra, de outro. Introduzindo a questão antropológica do gesto no campo das imagens, tal dualidade integraria a concepção do conceito de Phatosformel, ou fórmula do phátos, ou ainda, morfologia do páthos. A ideia de Warburg procura compreender e articular dois extremos: por um lado a atenção para "a animalidade do corpo em movimento; de outro, a atenção a sua 'alma', ou, pelo menos, a seu caráter psíquico e simbólico" (DIDI-HUBERMAN, 2013, p. 198).

Nem coisas viscerais, nem coisas siderais, nem céu mítico e infinito acerca do qual muito pouco se sabe, nem abismos fantasmáticos e monstruosos (o medo da floresta), nem figurações cósmicas, acima da cabeça, nem vísceras divinatórias, embaixo da terra -, a poética iconográfica montada pelos Espacialistas, no Atlas de Gonçalo M. Tavares, parece procurar localizar o homem justamente num centro neutro, lacunar: na atlas, vértebra-limite, ponto disjuntivo de articulação em sua possibilidade de rotação e movimento: entre o corpo e a cabeça; entre a fita métrica e o animalesco; entre a espacialidade e os materiais concretos, os elementos, as máquinas -; rotação, mobilidade, investida crítica sobre as formas, através da tatilidade, do corpo no corpo, da textura, da medição.

Roberto Esposito, na esteira de Jean Baudrillard, refere-se à emergência de um hiperrealismo contemporâneo, em que as coisas, lançadas no universo fantasmático do simulacro, já não se revestem mais de sua "rede simbólica", quando "o que hoje vem à tona é a própria coisa em sua absoluta nudez. Mas qual é o efeito do nosso encontro com ela? O que nos diz uma coisa desnudada, desprovida de ressonâncias simbólicas, aderente a si mesma até as bordas?” (ESPOSITO, 2016, p. 77). Para Esposito, pensar a problemática relacional entre as coisas e as pessoas é sobretudo procurar desatar um nó metafísico resultante de todo um trajeto de pensamento baseado numa dicotomia cartesiana que atravessou a modernidade. Nesse sentido, o corpo humano abre um "ângulo de visão externo à cisão que uma projeta sobre a outra” (ESPOSITO, 2016, p. 8), entrando em jogo aqui justamente uma posição diferente no espaço: "Aqui, mais do que colocado nele como os outros objetos, o corpo é o horizonte perceptivo em que eles se situam" (ESPOSITO, 2016, p. 101). Na abertura de uma 
realidade desnudada, desprovida de seu "suporte fantasmático", lançada nos limites de sua auto-aderência, de sua coincidência assombrosa e perfeita, um projeto textual-iconográfico como o Atlas do corpo e da imaginação parece justamente trazer o corpo nessa posição de diferença: reviramento lúdico e irônico dos pontos de vista, novos monstros, novas ligações, novos lugares de pensamento e de imaginação.

\section{Bibliografia}

BUCHLOH, Benjamin. “Atlas de Gerhard Richter: o arquivo anômico”. Revista do Programa de Pós-Graduação em Artes Visuais EBA - UFRJ. Série Temáticas. Rio de Janeiro. n. 19. V.23. p.195-209, 2012.

DIDI-HUBERMAN, Georges. A imagem sobrevivente - História da arte e tempo dos fantasmas segundo Aby Warburg. Trad. de Vera Ribeiro. Rio de janeiro: Contraponto, 2013.

. Ser Crânio. Lugar, contato, pensamento, escultura, tradução de Augustin de Tugny e Vera Casa Nova. Belo Horizonte: C/ Arte, 2009. . A semelhança informe - ou o gaio saber visual segundo Georges Bataille. Trad. Caio Meira, Fernando Scheib. Rio de Janeiro: Contraponto, 2015. . A imagem sobrevivente - História da arte e tempo dos fantasmas segundo AbyW arburg. Rio de Janeiro: Contraponto, 2013. . Atlas on le gai savoir inquiet - L'ail de l'bistoire, 3. Paris : Les Éditions de Minuit, 2011.

ESPOSITO, Roberto. As pessoas e as coisas. Trad. de Andrea Santurbano e Patricia Peterle, São Paulo: Rafael Zamperetti Competti Editor, 2016.

GUERREIRO, Julián Santos, TAVARES, Gonçalo M., MENDES DA ROCHA, Paulo. Pensar a casa. Conferências da Casa, 1. Matosinhos: Associação Casa da Arquitectura, 2011. SARDO, Delfim (2014) “Apresentação para o livro Atlas do corpo e da imaginação, de Gonçalo M. Tavares", < https://www.youtube.com/watch?v=-eNeL19cMsY> (último acesso em: 10/08/2017).

TAVARES, Gonçalo. Atlas do corpo e da imaginação. Lisboa: Ed. Caminho, 2013. . 1.Rio de Janeiro : Bertrand Brasil, 2005. . Breves notas sobre as ligações [llansol, molder e zambrano]. Florianópolis : Editora da casa, 2010.

. “Arquitetura, natureza e amor”. OPÚSCULO 14, Porto : Dafne Editora, 2008. . O Senhor Walser. Rio de janeiro: Casa da Palavra, 2008b. 